\title{
Multi-Channel Active Noise Control System Designs using Fuzzy Logic Stabilized Algorithms
}

\author{
DongJun Ahn ${ }^{1 *}$ \\ ${ }^{1}$ Department of Automotive Engineering, Ajou Motor College \\ 퍼지논리 안정화알고리즘을 이용한 다중채널 능동소음제어시스템 \\ 안동준 ${ }^{*}$ \\ ${ }^{1}$ 아주자동차대학 자동차계열
}

\begin{abstract}
In active noise control filter, IIR filter structure which used for control filter assures the stability property. The stability characteristics of IIR filter structure is mainly determined by pole location of control filter within unit disc, so stable selection of the value of control filter coefficient is very important. In this paper, we proposed novel adaptive stabilized Filtered_U LMS algorithms with IIR filter structure which has better convergence speed and less computational burden than conventional FIR structures, for multi-channel active noise control with vehicle enclosure signal case. For better convergence speed in adaptive algorithms, fuzzy LMS algorithmswhere convergence coefficient computed by a fuzzy PI type controller was proposed.

요 약 능동 소음제어 시스템에 사용되는 IIR 필터 구조는 구조적으로 안정성이 보장되어야 하며 이는 분모 전달 함수의 근이 단위원 내부에 존재하여야 한다. 따라서 이를 결정하는 제어 필터의 계수의 적절한 조정이 중요해 진다. 본 논문에서는 적응과정에서 불안정할 우려가 있는 IIR 필터 구조를 가지는 Filtered_U LMS 알고리즘에 안정화 알 고리즘과 수렴속도 향상을 위한 퍼지논리를 이용한 수렴계수 계산 알고리즘을 제안하였다. 제안한 알고리즘이 FIR 필터 구조 알고리즘보다 계산량이 적고 수렴특성이 우수함을 시뮬레이션을 통하여 보였다.
\end{abstract}

Key Words : Active Noise Control, Adaptive Filter, Stabilized Algorithm, multi channel LMS algorithm, IIR Filter, Fuzzy logic

\section{Multiple-channel active noise control systems}

Unwanted acoustic noise problems become more and more evident as increased numbers of large industrial equipment such as engines, blowers, fans, transformers, and compressors are in use. Mechanical vibration is another related type of noise that commonly creates problems in all areas of transportation and manufacturing, as well as many household appliances.
The traditional approach to acoustic noise control use passive techniques such as enclosures, barriers, and silencers to attenuate the undesired noise. These passive silencers are valued for their high attenuation over broad frequency range, but they are relatively large, costly, and ineffective at low frequencies. The attenuation of passive silencers is low when the acoustic wavelength is large compared to the silencer dimensions, such as body length or lining thickness.

ANC systems utilizing a microphone and an electronically

This research was financially supported by the Construction Technology Innovation Program (09 Technology Innovation E05) funded by Korea Institute of Construction \& Transportation Technology Evaluation and Planning(KICTEP) of Ministry of Land, Transportation and Maritime Affairs, Republic of Korea.

${ }^{*}$ Corresponding Author : Ahn Dong-Jun

Tel: +82-10-2240-3081 email: ahndj@motor.ac..kr

Received June 11, 2012

Revised July 31, 2012

Accepted August 9, 2012 
driven loud speaker to generate a canceling sound was first proposed in a 1936 patent by Lueg[1]. Recently, ANC systems needs highly precise control, temporal stability, and reliability performances. It is therefore desirable for noise canceller to be digital, where signals from electro-acoustic or electro-mechanical transducers are sampled and processed using DSP systems with enough speed and precision to execute sophisticated mathematical functions in real time[2 3].

In active noise control filter, IIR filter structure which used for control filter assures the stability property. The stability characteristics of IIR filter structure is mainly determined by pole location of control filter within unit disc, so stable selection ofvalue of control filter coefficient is very important.

In this paper, we proposed novel adaptive stabilized fuzzy Filtered_U LMS algorithms with IIR filter structure which has better convergence speed and less computational burden than conventional FIR structures, for multi-channel active noise control with vehicle enclosure signal case.

Fig 1. Shows that multi-channel ANC systems using $\mathbf{J}$ reference sensors, $\mathrm{K}$ parallel adaptive filters and corresponding secondary sources, and $\mathrm{M}$ error sensors[4].

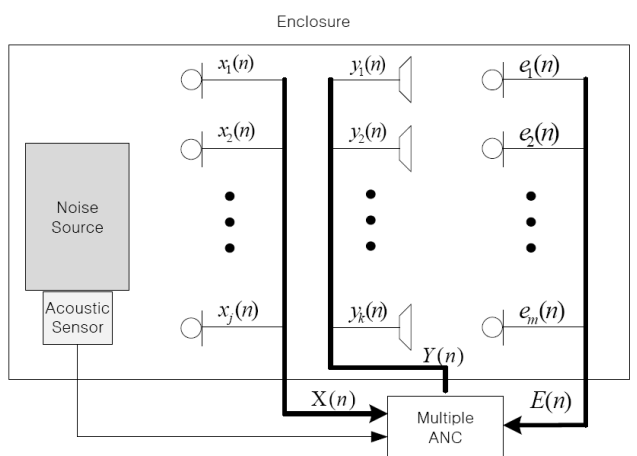

[Fig.1] 3-Dimensional Active Noise Cancelling Systems

Fig. 1 can be simplified to block diagram shown in Fig. 2. The elements of the vector $d(n)$ are the primary noise components of the error sensor outputs. The matrix $\mathrm{P}(\mathrm{z})$ represents $\mathrm{M} \times \mathrm{J}$ primary path transfer function, the matrix $\mathrm{S}(\mathrm{z})$ represents $\mathrm{M} \times \mathrm{K}$ secondary path transfer functions.

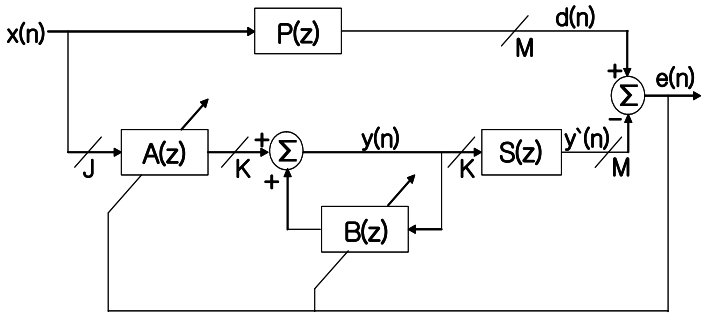

[Fig. 2] Block diagram of multi-channel ANC Systems

The output of k-th secondary transfer function as follows.

$$
y_{k}(n)=\sum_{j=1}^{J} a_{k j}^{T}(n) x_{j}(n)+\sum_{i=1}^{K} b_{k i}^{T}(n) y_{i}(n-1)
$$

for $k=1,2, \cdots, K$, where

$a_{k j}(z) \equiv a_{k j, 0}(n)+a_{k j, 1}(n) z^{-1}+a_{k j, 2} z^{-2}+\cdots+a_{k j, L-1}(n) z^{L-1}$

$b_{k i}(z)=b_{k i, 1}(n) z^{-1}+b_{k i, 2}(n) z^{-2}+b_{k i, 3}(n) z^{-3}+\cdots+b_{k i, I}(n) z^{I}$

For unknown or time varying equations of adaptive LMS algorithms is as follows.

$$
\begin{aligned}
& a_{k j}(n+1)=a_{k j}(n)+\mu_{a} \sum_{m=1}^{M} x_{j k m}^{\prime}(n) e_{m}(n) \\
& b_{k i}(n+1)=b_{k i}(n)+\mu_{b} \sum_{m=1}^{M} y_{i k m}^{\prime}(n) e_{m}(n)
\end{aligned}
$$

where

$$
\begin{aligned}
& x_{j k m}^{\prime}(n) \equiv \hat{S}_{m k}(n) * x_{j}(n) \\
& y_{i k m}^{\prime}(n) \equiv \hat{S}_{m k}(n) * y_{i}(n)
\end{aligned}
$$

are respectively, the filtered reference and output signal vectors. In order to get optimal control filter coefficients, must be consider the effect of secondary path transfer functions $\hat{S}_{m k}(n)$, and then Fig. 2 modified as Fig. 3(J=1, $\mathrm{M}=2, \mathrm{~K}=2$ ). These methods are called by Filtered_U LMS algorithms. 


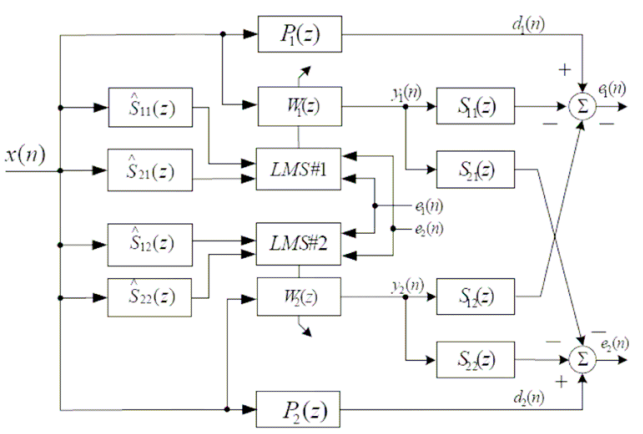

[Fig. 3] Multi-channel(1x2x2) ANC System

\section{Stabilized IIR filter structure}

An adaptive IIR filter structure was considered the feedback as a part of the overall plant, it allows the system to dynamically track changes in the secondary and feedback paths during cancellation operations. But Eq. 6 implies the adaptive IIR filter would be try to generate poles corresponding to the ideal response, and since the trajectory of the filter poles during convergence is rather unpredictable, one or several poles could be more outside the unit circle, leading to instability. The problem with unstable filter poles can be solved such as leaky LMS algorithm[5]. However, This methods has slow convergence characteristicsof adaptive algorithms.

In this paper, we proposed the stabilized algorithms for adaptive IIR filter structure[6 7] with multi-channel ANC systems which shows in Fig. 4. Eq. 7 represent proposed algorithms that pre-filter polynomial matrix $\mathrm{F}(\mathrm{z})$ which multiply by control filter polynomial matrix $\mathrm{B}(\mathrm{z})$. Pre-filter polynomial $f(z)$ has a role that moving the unstable filter poles in transient state, and then return originally in steady state.

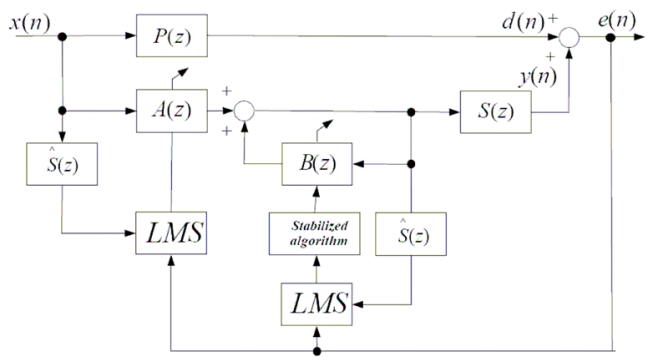

[Fig. 4] Stabilized Filtered_U ANC System

$$
\mathbf{F}(z)=\left[\begin{array}{cccc}
f_{11}(z) & f_{12}(z) & \cdots & f_{1 K}(z) \\
f_{21}(z) & \cdots & \cdots & f_{2 K}(z) \\
\vdots & \ddots & \ddots & \vdots \\
f_{K 1}(z) & \cdots & \cdots & f_{K K}(z)
\end{array}\right]=\mathbf{I}_{K}-k \mathbf{B}(z)
$$

where $\mathbf{I}_{k}$ is $\mathrm{K} \times \mathrm{K}$ unit matrix, and then pre-filter polynomial is

$$
\begin{aligned}
& f_{k k}(z)=1+k(n) b_{k k, 1}(n) z^{-1}+k^{2}(n) b_{k k, 2}(n) z^{-2}+ \\
& \cdots+k^{I}(n) b_{k k, I}(n) z^{-I}
\end{aligned}
$$

where $0 \leq \boldsymbol{k} \leq 1$, calculation of coefficient $\mathrm{k}$ is as follows

$$
k(n+1)=\lambda k(n)+(1-\lambda) \quad, \quad k(0)=0, \quad 0 \leq \lambda \leq 1
$$

\section{Fuzzy logic LMS algorithm}

LMS algorithms which were used for control filters, assure the convergence property, and computational burden of these algorithms are proportionate to the number of filter taps.However, slow convergence speed of the LMS algorithm is a major dis-advantage. The convergence speed of the LMS algorithm is mainly determined by the value of the convergence coefficient, so optimal selection of the value of the convergence coefficient is very important. Convergence speed of the normalized LMS algorithm is relatively faster than the conventional LMS algorithm[8]

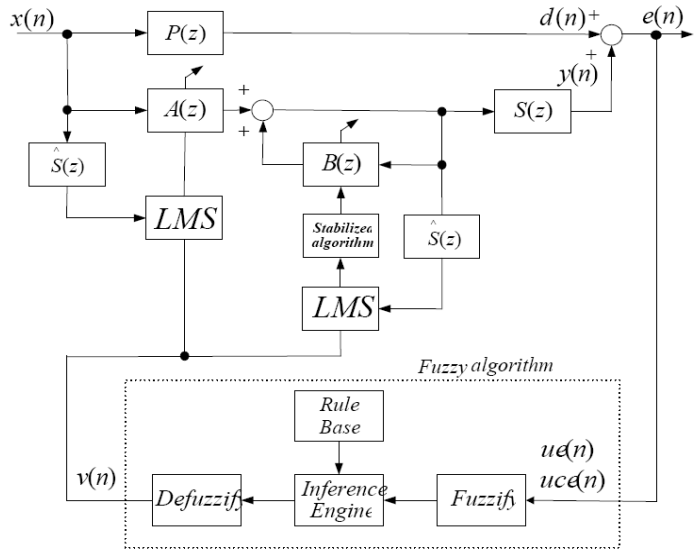

[Fig. 5] Stabilized adaptive fuzzy LMS ANC algorithm 
In this paper, a fuzzy LMS algorithm where the convergence coefficient is computed by a fuzzy proportional controller was proposed[9] in Fig. 5.

The estimation errors and mis-adaptation degrees were used for input of the fuzzy logic LMS algorithm in Eq. (11).

Proposed fuzzy logic LMS algorithms is

$$
W(n+1)=W(n)+\frac{v(n)}{(L+1)} e(n) x(n)
$$

where $v(n)$ is output of fuzzy inference engine, and $\mathrm{L}$ is order of control filter.

Calculation procedures of $v(n)$ is as follows.

1) Calculate the estimationerror and change of error as follows in Eq. 12 13.

$u e(n)=\alpha_{1} u e(n-1)+\left(1-\alpha_{1}\right) \frac{\|e(n) x(n)\|}{(L+1)}$

$\left.u c e(n)=\alpha_{1} u c e(n-1)+\left(1-\alpha_{1}\right) \| u e(n)\right)-u e(n-1) \|$

where $\alpha_{1}$ is forgetting factor of $u e(n), u e(n)$ is quantitative measurement of mis-adaptation which obtained by norm of cross correlations of input signal and estimation error signal vector, and $u c e(n)$ is result of smoothing filter which norm of change of error signal ue(n).

2) Define the membership function of fuzzy input/ output variable $u e(n), u c e(n), v(n)$, respectively, as shown Fig. 6.

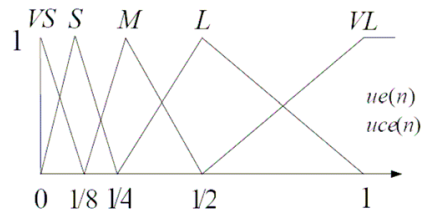

(a) $m_{u e}(U E), m_{u c e}(U C E)$

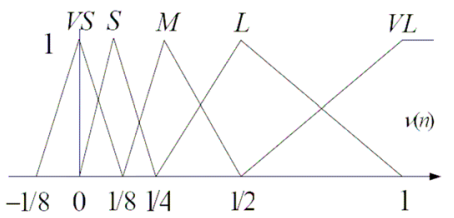

(b) $m_{v}(v)$

[Fig. 6] Membership function of fuzzy input/output variables
3) Define the linguistic control rule for decision of convergence coefficient that fast convergence characteristics as Table 1.

[Table 1] linguistic control rules for decision of convergence coefficient

\begin{tabular}{|c|c|c|c|c|c|}
\hline uce & VS & S & M & L & XL \\
\hline VS & VL & L & M & S & VS \\
\hline S & VL & VL & M & M & S \\
\hline M & VL & VL & L & L & M \\
\hline L & VL & VL & VL & VL & L \\
\hline XL & VL & VL & VL & VL & VL \\
\hline
\end{tabular}

where VS : very small, $\mathrm{S}:$ small, $\mathrm{M}:$ medium $\mathrm{L}:$ large, $\mathrm{XL}$ : very large, respectively.

4) Calculate max-min composition operation

$v^{0}(n)=\max \left[\sum_{i=1}^{N} \min \left[m_{U E i}\left(u e_{i}\right), m_{U C E i}\left(u e_{i}\right), m_{v i}\left(v_{i}\right)\right]\right]$

where $v^{0}(n)$ is fuzzy output variable.

5) Calculate the crisp output $v(n)$, using discrete center of gravity methods (defuzzify methods)

$v(n)=\frac{\sum_{i=1}^{N}\left(v^{0}(n) m_{v}\left(v_{i}\right)\right)}{\sum_{i=1}^{N}\left(m_{v}\left(v_{i}\right)\right)}$

\section{Computer simulation}

[Table 2] Common simulation parameters

\begin{tabular}{|c|c|c|}
\hline Item & \multicolumn{2}{|c|}{ Data } \\
\hline Transfer Function & \multicolumn{2}{|c|}{$1 \times 2 \times 2$ multi model(order : 25 ) } \\
\hline Sound speed & \multicolumn{2}{|l|}{$340[\mathrm{~m} / \mathrm{s}]$} \\
\hline Sampling frequency & \multicolumn{2}{|l|}{$2[\mathrm{kHz}]$} \\
\hline Calculation step & \multicolumn{2}{|c|}{ 10,000step(5 sec.) } \\
\hline Reference signal & \multicolumn{2}{|c|}{ Gasoline Engine muffler } \\
\hline $\begin{array}{l}\text { Estimated secondary } \\
\text { transfer function }\end{array}$ & \multicolumn{2}{|c|}{ FIR structure, 192tap } \\
\hline $\begin{array}{l}\text { Control filter tap } \\
\text { (conventional) }\end{array}$ & \multicolumn{2}{|c|}{ FIR structure, 192tap } \\
\hline $\begin{array}{l}\text { Control filter tap } \\
\text { (proposed) }\end{array}$ & $\begin{array}{l}\text { Numerator } \\
: 96\end{array}$ & $\begin{array}{l}\text { Denumerator } \\
: 6\end{array}$ \\
\hline Convergence coefficient & \multicolumn{2}{|l|}{0.000015} \\
\hline
\end{tabular}


To show effectiveness of proposed systems, computer simulations was performed by under such condition as Table 2 in given common parameters. Simulation model is applied by $1 \times 2 \times 2$ multi-channel models[4].

To reduce the computation burden in fuzzy inference engine that overcome real time implementation problem, make the look-up table which composed of convergence coefficient that calculation result of fuzzy inference engine.

Fig. 7 is represented by pole-zero location plotting of transfer function of primary source and secondary sources path(order : 25).

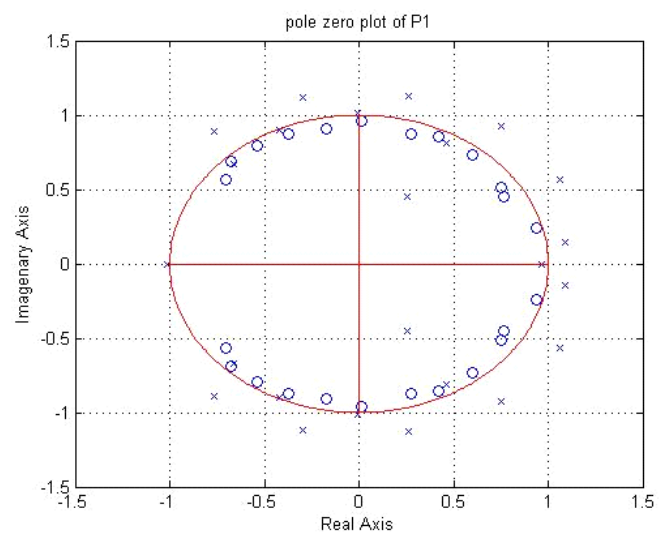

(a) primary source $(\mathrm{P} 1)$

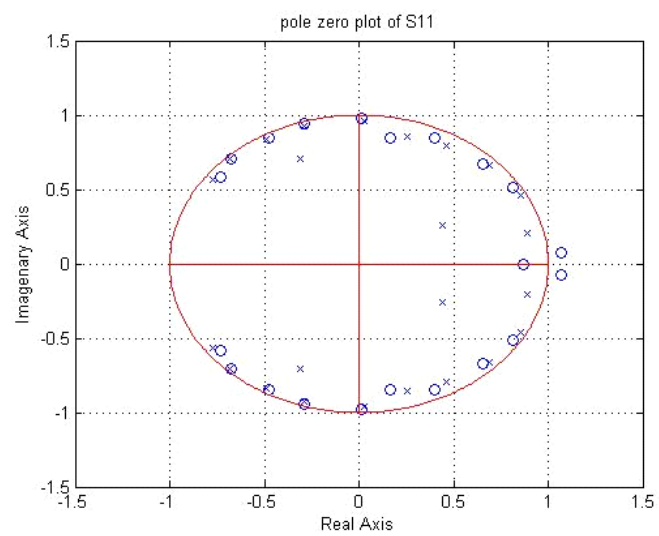

(b) secondary source(S11)

[Fig. 7] pole-zero location plotting of transfer function

Fig. 8 is estimation result of off-line estimation of secondary path transfer function.(FIR structure, 192 tab)

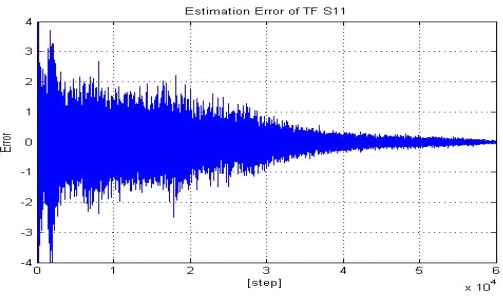

(a) $\mathrm{S} 11$

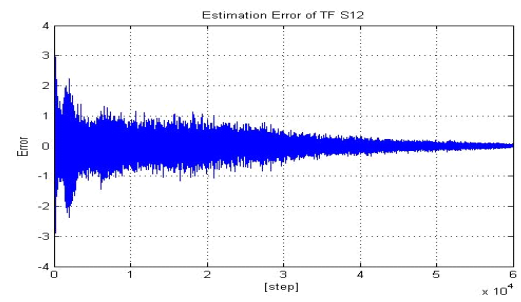

(b) $\mathrm{S} 12$

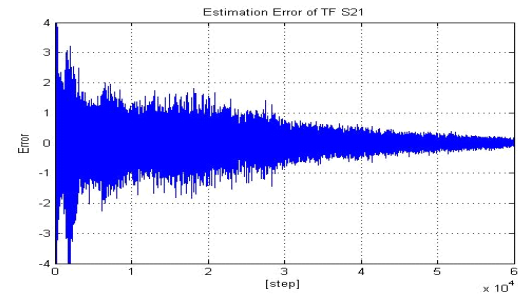

(c) S21

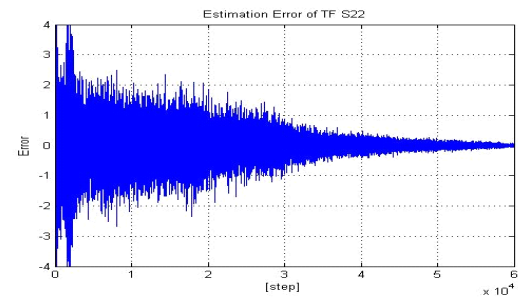

(d) S22

[Fig. 8] off-line estimation of secondary path transfer functions
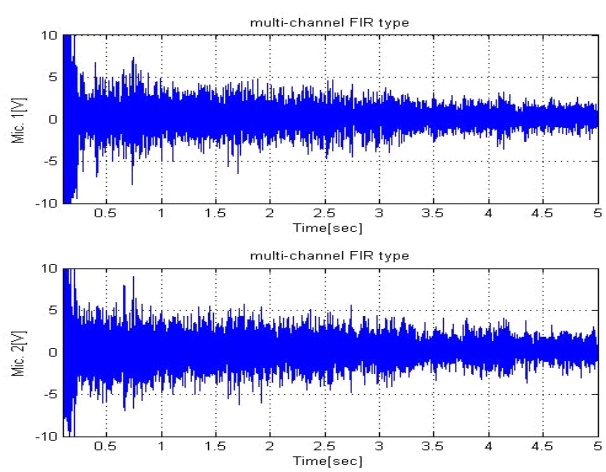

(a) conventional algorithms(FIR structure) 

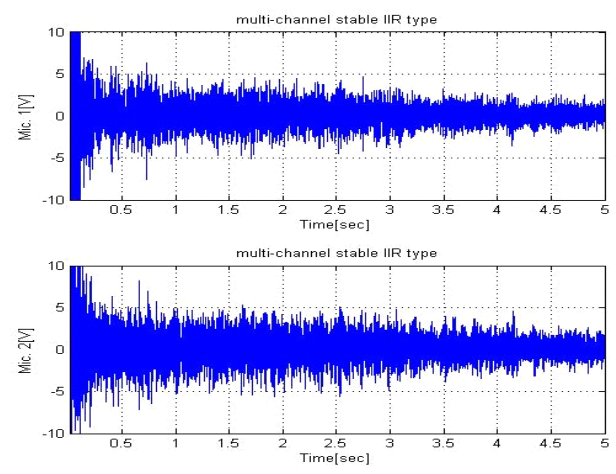

(b) Stable IIR structure algorithms
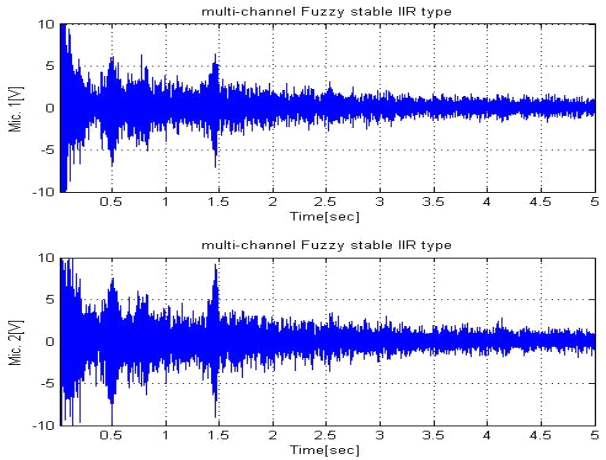

c) proposed algorithms(Fuzzy Stable IIR)
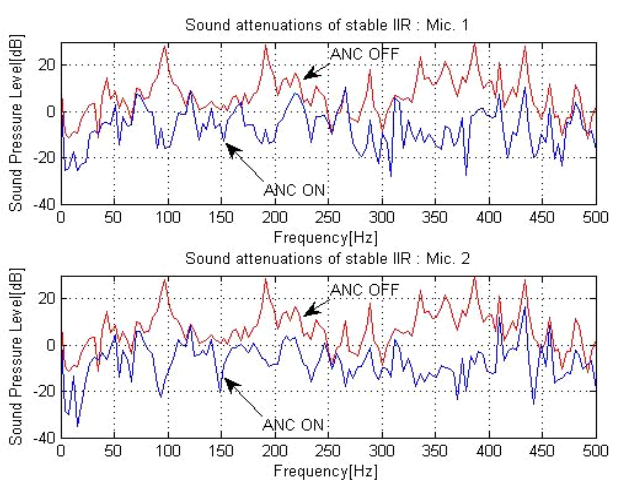

(d) sound attenuation of proposed algorithms

[Fig. 9] Comparison of conventional and proposed algorithms

Fig. 9 is simulation result of conventional algorithm and proposed algorithms, respectively. Proposed algorithm is shown that better convergence speed and computational burden than conventional algorithm

\section{Conclusion}

In active noise control filter, IIR filter structure which used for control filter assures the stability property. The stability characteristics of IIR filter structure is mainly determined by pole location of control filter within unit disc, so stable selection ofthe value of control filter coefficient is very important.In this paper, we proposed novel adaptive stabilized Filtered_U LMS algorithms with IIR filter structure which has better convergence speed and less computational burden than conventional FIR structures, for multi-channel active noise control with vehicle enclosure signal case. For better convergence speed in adaptive algorithms, fuzzy LMS algorithms was proposed where convergence coefficient computed by a fuzzy PI type controller was proposed. Computer simulations were performed to show the effectiveness of proposed algorithms with 3-dimensional model problem.

\section{References}

[1] Lueq P., "Process of silencing sound oscillations," U.S. Patent 2043, 416, 1934.

[2] Elliott S.J. and Nelson P.A., "The active control of sound,"Electronics and Communication Eng. Jour., pp.127-136, 1990.

[3] Nelson P.A. and Elliott S.J., "Active noise control: A tutorial review," Proceedings of the International Symposium on Active Control of Sound and Vibration, Tokyo, Japan, pp.45-74, 1991.

[4] Kuo S.M and Morgan D.R..Active Noise Control Systems,John Wiley, 1995.

[5] Widrow B. and Stearns S.D., Adaptive Signal Processing, Englewood Cliffs, NJ: Prentice-Hall, 1985.

[6] Muhammad T. and Masahide A., Masauki K., "A New Variable Step Size LMS Algorithm-Based Method for Improved Online Secondary Path Modeling in Active Noise Control Systems," IEEE Trans. on Audio, Speech and Language Processing, (2006) Vol. 14, No. 2, 720-726.

[7] Nam H. D. and Seo S. D., Yoon K. J., Ahn D. J., "Stabilized multi-channel IIR filters for active control of noise in a duct," ICSV13-Vienna, Austria, 2006.

[8] Cheralu M. and Teodorescu H. N., Dumitrascu C., "A fuzzy LMS algorithm," Proceeding of the 
international conference on Fuzzy Logic \& Neural Networks, Japan, Isuka, pp. 107-110, 1990.

[9] D. J. Ahn, "Design of adaptive filters for active noise control," Ph. D. theses, S. Korea, Graduate School of Dankook Univ, 1995.

Dong-Jun Ahn

[Regular member]

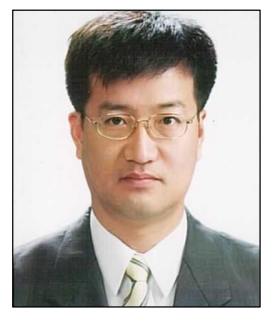

- Feb. 1986 :

SungKyunKwan Univ., BS

- Apr. 1988 : Dankook Univ., MS

- Feb. 1998 Feb. 1995 :

Dankook Univ., , Ph D.

- Mar. $1995 \sim$ current :

Professor of Ajou Motor College

$<$ Research Interests $>$

Signal Processing, Adaptive Filter, Active Noise Control, DSP algorithm, MicroController applications 